compared with those using the diaphragm when they refer to these two conditions occurring among users of the oral contraceptive?

I would be grateful if this point could be clarified as the text does not do so.

C G H MAIDMENT

University College Hospital,

London WC1

** We sent a copy of this letter to Dr Mann,

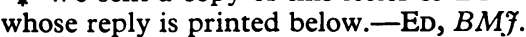

SIR,-Table II in our paper certainly does refer to excess mortality attributable to oral contraceptives. This is clearly stated in the last line of the table but I do accept that it might have been helpful to have made this point clear also in the table heading.

J I MANN University Department of
Social Medicine, Oxford

\section{Diagnosis of brain death}

SIR,-While we welcome wholeheartedly the clarification provided by the statement concerning the diagnosis of brain death issued by the Conference of Medical Royal Colleges and their Faculties in the United Kingdom (13 November, $p$ 1187) we feel that it is unfortunate that the two references to electroencephalographic technique are incorrectly cited. They should read: "International Federation of EEG Societies. Electroencephalography and Clinical Neurophysiology, 1974 37, 530; 1970, 28, 536."

Pamela F Prior

DONALD SCOTT

The London Hospital (Whitechapel)

London E1

\section{Additives to intravenous fluids}

SIR,-We were interested to read in your leading article on this subject ( 31 July, p 264) that "continuous intravenous infusion is indicated only for antibiotics which are too toxic or irritant to be given intermittently-for example, tetracyclines and fusidic acid." We should like to report the successful use of a rapid intermittent intravenous infusion of diethanolamine fusidate with cloxacillin in a boy with staphylococcal osteomyelitis and septicaemia.

A 7-year-old boy presented with a $24-\mathrm{h}$ history of pain since being kicked on the left ischium. Examination revealed a sick, limping child with a temperature of $38.2^{\circ} \mathrm{C}$. The soft tissue over the left ischium was tender, but passive movement of both hips was possible. A clinical diagnosis of osteomyelitis was confirmed by blood culture taken on admission, which grew a Staphylococcus aureus resistant to benzylpenicillin, ampicillin, tetracycline, and neomycin but sensitive to methicillin, cloxacillin, chloramphenicol, erythromycin, trimethoprim, clindamycin, sodium fusidate, and gentamicin.

The following day the ischium became exquisitely tender, the temperature rose to $39^{\circ} \mathrm{C}$, and the peripheral white cell count was $29 \times 10^{9} / 1$ $\left(29000 / \mathrm{mm}^{3}\right), 88 \%$ of which were neutrophils. Intravenous benzylpenicillin $(0.5 \mathrm{~g}$ four-hourly) and cloxacillin $(0.5 \mathrm{~g}$ four-hourly) were given in dextrose saline. Four blood cultures taken during the first two days after admission grew Staph aureus with the same antibiotic sensitivity pattern.
Two days later, after two operations which had hown no pus formation, the child developed a paralytic ileus and anuria. A rapid intravenous infusion of diethanolamine fusidate $(290 \mathrm{mg}$ equivalent to $250 \mathrm{mg}$ of sodium fusidate) in dextrose saline $(540 \mathrm{ml})$ was then given over $15 \mathrm{~min}$ every four hours, the benzylpenicillin being with drawn but the cloxacillin injections continued. Within $24 \mathrm{~h}$ the patient was apyrexial and subsequently made an uneventful recovery. Intermitten intravenous infusions of diethanolamine fusidate with cloxacillin were continued for four days and he took oral flucloxacillin $(0.5 \mathrm{~g})$ with sodium fusidate $(250 \mathrm{mg})$ four times a day for severa months after discharge.

As one possible cause for the failure of this patient to respond to intravenous cloxacillin was its inactivation in the dextrose saline infusion ${ }^{1}$ th antibiotic activity was measured after mixing cloxacillin $(0.5 \mathrm{~g})$ with normal saline, dextrose saline, and $5 \%$ dextrose infusions $(540 \mathrm{ml})$. There was no loss of antibacterial activity during the six hours for which these infusions were left at room temperature.

It is noteworthy that, although cloxacillin was ineffective, the combination of diethanolamine fusidate with cloxacillin rapidly cured this child's staphylococcal septicaemia. The history illustrates the value of rapid inter mittent intravenous infusions of diethanolamine fusidate and cloxacillin in staphylococcal osteomyelitis complicated by septicaemia.

In a further study of eight normal subjects a rapid intravenous infusion of diethanolamine fusidate $(580 \mathrm{mg}$, equivalent to $500 \mathrm{mg}$ of sodium fusidate) was given over $15 \mathrm{~min}$. Thi was well tolerated. Thrombophlebitis ${ }^{2}$ did not follow these infusions in any normal subject or in the child with septicaemia. There was also no evidence of haemolysis. ${ }^{3}$ Thus in nine subjects intermittent intravenous infusions of diethanolamine fusidate given over $15-20 \mathrm{~min}$ were safe and well tolerated. These may be life-saving in acute staphylococcal osteomyelitis and septicaemia.

R L PARSONS JOHN P BEAVIS G M PADDOCK

Jill A DAVID J R TROUNCE

Guy's Hospital

1 Simberhoff, M S, et al, New England fournal of Medicine, 1970, 283, 116 .
Copperman, I J, British fournal of Clinical Practice, 1972, 26, 83.

\section{New enterotoxinogenic bacteria isolated}

SrR,-Dr T Wadström and his colleagues (5 June, $p$ 1401) reported the isolation of enterotoxinogenic Escherichia coli from 28 out of 640 patients with diarrhoea in Sweden and observed that 24 of these 28 had been abroad during the two weeks before sampling. Studies in the USA ${ }^{1}$ have shown enterotoxinogenic $E$ coli to be an important cause of diarrhoea in travellers to Mexico. We have recently completed a small survey of patients admitted to hospital in the United Kingdom with persistent diarrhoea which first developed during travel in Africa and Asia.

Sixteen adult patients were included in the survey. Faecal specimens obtained shortly after admission to hospital were examined by direct microscopy for the presence of ova and cysts and by routine methods for salmonellae, shigellae, and vibrios. In addition five representative colonies selected from MacConkey agar cultures were identified biochemically and those identified as $E$ coli were serotyped using antisera for somatic antigens $\mathrm{O} 1-\mathrm{O} 163$ and flagella antigens $\mathrm{H} 1-\mathrm{H} 56$. A representative culture of each serotype found in each patient was tested for enterotoxin production. One representative culture of any other species of Enterobacteriaceae from each patient was similarly tested. The infant mouse test ${ }^{2}$ was used for the detection of heat-stable enterotoxin (ST) and the $\mathrm{CHO}$ cell ${ }^{3}$ and $\mathrm{Y} 1$ cell $^{4}$ tests were used to detect heat-labile enterotoxin (LT).

Five patients had Giardia lamblia in their stools and one patient was excreting cysts of Entamoeba histolytica. Salmonellae, shigellae, and vibrios were not found. Only 12 patients were found to be excreting $E$ coli; in two patients only Gram-positive organisms were found, one patient excreted only Citrobacter freundii and one excreted a mixture of $C$ freundii, Hafnia alvei, and Enterobacter sp. A total of $28 E$ coli and seven other organisms were tested for enterotoxin production; these included $2 C$ freundii, 2 Enterobacter sp, 1 Proteus sp, 1 Klebsiella sp, and 1 Hafnia alvei. None of the organisms produced ST, but LT production was demonstrated in $E$ coli from two patients who had travelled overland to Nepal. In both patients the serotype was O114 H49.

These results support the possible role of enterotoxinogenic $E$ coli as a cause of diarrhoea in adults. The study in the USA ${ }^{1}$ was concerned with acute diarrhoea developing shortly after arrival in Mexico. The present study suggests that enterotoxinogenic $E$ coli may also be implicated in diarrhoea which developed overseas but persisted for up to six weeks. Further studies are required and we would be pleased to receive cultures of $E$ coli isolated from patients returning to the UK with diarrhoea which developed while they were abroad or who develop diarrhoea within a few days of returning to the UK. Such strains should be sent to Dr B Rowe at the address given below.

We acknowledge the assistance of Dr R Grüneberg and the staff of the Bacteriology Department, University College Hospital, London.

G M BURNHAM

Hospital for Tropical Diseases,

Sylvia M SCOTLAND

R J GROSS

B ROWE

Salmonella and Shigella Reference

Laboratory,
Central Public Health Laboratory, Colindale Avenue,

Sack, D A, et al, Lancet, 1975, 2, 239.

Dean, A G, et al, Fournal of Infectious Diseases, 1972, 125, 407.
Guerrant, R L, et al, Infection and Immunity, 1974, Guerrant, R L, et al, Infection and Immunity, 1974,
10, 320.
Donta, S , Moon, H W, and Whipp, S C, Science, 1974, 183, 334 .

\section{Glutethimide and enzyme induction}

SIR,-We would agree with Drs J A Mathews and D A H Yates (23 October, p 1014) that the enzyme-inducing properties of glutethimide should be more widely appreciated. Glutethimide has been shown to shorten warfarin plasma half lives, ${ }^{1}$ to decrease steady-state plasma warfarin levels, ${ }^{2}$ and thus to decrease the hypoprothrombinaemic effect of warfarin. ${ }^{3}$

A recent pilot study of enzyme induction in man has provided information on the time course of this effect. Three healthy male 
volunteers received glutethimide $500 \mathrm{mg}$ every evening for five days. Twenty-four-hour D-glucaric acid excretion was measured on a control day and daily thereafter. The results are shown in the figure.

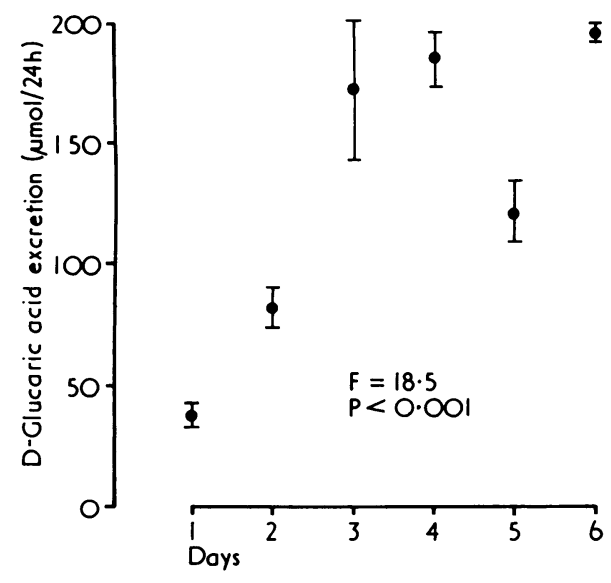

D-Glucaric acid excretion (mean \pm SEM) in three healthy

male subjects given glutethimide on days 2 to 6 .
Conversion: SI to traditional units-D-Glucaric acid: $1 \mu \mathrm{mol} / 1 \approx 132 \mu \mathrm{g}$.

There was clear evidence of enzyme induction within two days of the first administration. As change in D-glucaric acid excretion has been shown to correlate with change in antipyrine half life ${ }^{4}$ important drug interactions could be expected at this time. Changes in steady-state plasma levels of warfarin would take much longer to develop because of the drug's long half life. These results suggest, however, that as little as two doses of glutethimide could alter the dosage requirements of drugs with shorter half lives such as cortisone.

Clive Roberts

LYN JACKSON MAMOUN HOMEIDA

Departments of Pharmacology
and Medicine, and Medicine,
University of Bristo

1 Corn, M, Thrombosis et Diathesis Haemarrhagica, 1966, 16, 606

MacDonald, M G, et al, Clinical Pharmacology and Therapeutics, 1969, 10, 80 .

3 Udall, J A, American fournal of Cardiology, 1975, 35, 67.

avis, M, et al, British fournal of Clinical Pharmacology, 1974, 1, 253.

\section{Progesterone or progestogens?}

SiR,-Your expert's answer (11 September, p 634) to the question "Does progesterone have a place on treating premenstrual and postpartum depression ?" assumes, quite falsely, that progestogens are a convenient oral substitute for the natural hormone progesterone. They are not, and medical advances in psychiatry, gynaecology, and obstetrics are held up by the failure of clinicians to appreciate this fact. Both are valuable drugs with specific indications for their use.

By definition progestogens are drugs which cause endometrial withdrawal bleeding in immature oestrogen-primed rabbits (Clauberg's test) in the same manner as progesterone. On this test many progestogens are more potent than progesterone; D-norgesteral is 2000 times more potent. However, whereas progesterone causes endometrial hypertrophy, some progestogens cause endometrial atrophy. Some are oestrogenic-for example, 19- nortestosterone derivatives-and other progestogens are free from oestrogenic activityfor example, medroxyprogesterone. Some, especially the 19-nortestosterone derivatives, are androgenic and in pregnancy cause masculinisation of the female fetus, but progesterone is completely free from androgenic effects on the fetus. ${ }^{1}$ Progestogens, in fact, cause a reduction in plasma progesterone whereas, of course, progesterone does not. ${ }^{2}$

Progesterone is also formed in the adrenals, where it is converted from cholesterol and becomes the precursor of all corticosteroids. Progesterone is responsible for the transport of glucocorticoids attached to the alpha globulin of the plasma and it is one of the few steroids with a high affinity for this binding protein and can cause displacement of cortisol to the free active fraction. ${ }^{3}$ These glucocorticoids maintain liver glycogen and help to maintain the blood sugar levels. Progestogens cannot mimic these actions of progesterone.

Progestogens are the drugs of choice as contraceptives and where endometrial atrophy is required, as in endometriosis and menorrhagia. Progesterone is the drug of choice in premenstrual and postpartum depression and premenstrual syndrome. Progesterone cannot be absorbed orally but has good absorption by the vaginal and rectal routes. As the biological half life of progesterone is short the dose and timing of administration is crucial if physiological levels are to be maintained and this may call for twice-daily administration.

K DALTON

London W1

' Zussman, J U, Zussman, P P, and Dalton, K, Society for Research in Child Development, Denver, Colorado, April 1975. Awaiting publication.

Johansson, E D B, Acta Endocrinologica, 1971, 68, 779 Harper, H A, Review of Physiological Chemistry, 12th edn, p 482. Los Altos, Lange, 1969.

of Obs, S J, and Johansson, E D B, American fournal

110, 4.

***Our expert writes: "I am aware of Dr Dalton's work but I have found that people do get better on the treatment I advocatedED, BMJ.

\section{Low-dose progestogens and ectopic pregnancy}

SIR,-The low-dose progestogens account for about $35 \%$ of all oral contraceptives now used in Finland. In this department we have found a total of 15 cases of ectopic pregnancy in patients using low-dose progestogens for contraception in the period from 1 January 1973 to the end of August 1976. Table I shows the total number of ectopic pregnancies and the number and incidence of ectopic pregnancies during low-dose progestogen contraception annually in this period. Table II

TABLE I-Total number of ectopic pregnancies and number and incidence of ectopic pregnancies during low-dose progestogen contraception

\begin{tabular}{c|c|c|c}
\hline \multicolumn{1}{|c|}{ Year } & $\begin{array}{c}\text { Ectopic } \\
\text { pregnancies }\end{array}$ & $\begin{array}{c}\text { Ectopics } \\
\text { during } \\
\text { progestogen } \\
\text { contraception }\end{array}$ & $\%$ \\
\hline 1973 & 37 & 1 & $2 \cdot 7$ \\
1974 & 52 & 4 & $7 \cdot 7$ \\
$\begin{array}{l}1975 \\
1976 \text { until end of } \\
\text { August) }\end{array}$ & 47 & 7 & $14 \cdot 9$ \\
\hline Total & 37 & 3 & $8 \cdot 1$ \\
\hline
\end{tabular}

TABLE II-Calculated use of different progestogens in women years, number of ectopic pregnancies in 1973-5, and risk of ectopic pregnancy for each progestogen

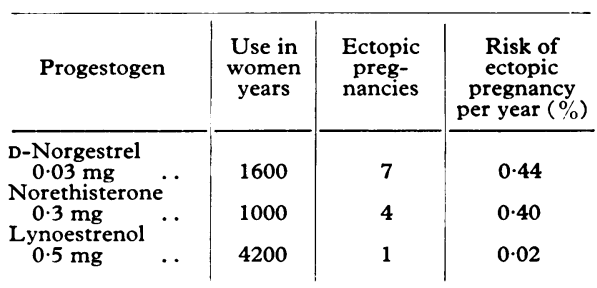

shows cases of ectopic pregnancy for different progestogens used for contraception.

On the basis of these figures it is possible to estimate the absolute risk of ectopic pregnancy carried by different progestogens (table II). Thus for D-norgestrel $0.03 \mathrm{mg}$ the risk is approximately 1 per 230 users and for norethisterone $0.3 \mathrm{mg} 1$ per 250 users per year. Lynoestrenol $0.5 \mathrm{mg}$ has a very significantly $(P<0.001)$ smaller risk of 1 per 4200 users per year. According to the manufacturers the Pearl index for D-norgestrel is 1.0 , for norethisterone 1.4 , and for lynoestrenol 0.4 . If the figures are true it can be estimated that almost every second pregnancy with Dnorgestrel and every third with norethisterone are ectopic. For lynoestrenol this risk is one ectopic pregnancy in 17 pregnancies.

Our study confirms the suggestion ${ }^{12}$ that the risk of ectopic pregnancy is considerable among the users of low-dose progestogens. Our study also shows that certain preparations carry an exceptionally high risk of extrauterine pregnancy. From a therapeutic point of view, the possibility of ectopic pregnancy has to be considered whenever the low-dose progestogens are prescribed for contraceptive purposes. Also the possibility of ectopic pregnancy must always be taken into consideration in patients developing pain in the lower abdomen while on low-dose progestogens, irrespective of their previous bleeding pattern.

PEKKa LiUkKo Risto ERKKOLA

Department of Obstetrics and Gynaecology, of Turku, Turku, Finland Smith, M, et al, British Medical fournal, 1974, 3, 104
Beral, V, British fournal of Obstetrics and Gynaecology,

\section{Prazosin in hypertension}

SIR,-I note with interest Professor Clive Rosendorff's observations (28 August, p 508) concerning the dose dependency of the initial side effects of prazosin. In this department we have used this hypotensive agent on over 150 patients and confirm his findings.

Recently 24 hypertensive patients (12 female) were studied with a single $1-\mathrm{mg}$ tablet. Supine and erect blood pressures were recorded at $15-\mathrm{min}$ intervals before and after the dose for up to $270 \mathrm{~min}$. Six had had no previous therapy and 18 were uncontrolled on other drugs, chiefly thiazides or beta-blockers or a combination of both. In 10 there were no symptoms of postural hypotension. In this group there was a mean maximum erect blood pressure reduction of $22 / 14 \mathrm{~mm} \mathrm{Hg}$ (from $165 / 109 \mathrm{~mm} \mathrm{Hg}$ ) at an average of $110 \mathrm{~min}$ after the dose. The mean pulse rate remained unchanged. The remaining 14 patients had symptoms of postural hypotension; in three 